\title{
IMPACT OF COVID-19 ON US DOLLAR EXCHANGE RATE IN SRI LANKA: A TIME SERIES ANALYSIS
}

\author{
Karunathilaka, H.S ${ }^{1}$, Dharmadasa, H.K.T.D ${ }^{1}$, Kumarasinghe, K.K.M.H ${ }^{1}$ \\ and \\ Premarathne, $\mathrm{W}^{1}$
}

Department of Management and Finance, Faculty of Management, Social Sciences and Humanities, General Sir John Kotelawala Defence University, Rathmalana, Sri Lanka ${ }^{1}$

\begin{abstract}
The exchange rate is considered a key financial variable that affects the decisions of exporters, importers, investors, bankers, tourists, and policymakers in developed and developing countries. Exchange rate fluctuations determine the international reserves, international investment portfolios, the competitiveness of exports and imports, and the costs incurred by tourists. Understanding the behaviour of exchange rates is important for developed and developing countries to formulate and modify economic policies. Therefore, this research studies the influence of COVID-19 on the USD sell exchange rate in Sri Lanka using a time series analysis. The study was conducted using daily exchange rates from 19 November 2019 to 18 October 2020, and it attempted to obtain the best ARIMA model: $A R(1), A R(6), A R(14), A R(27), M A(3), M A(8), M A(11)$. Finally, the USD sell exchange rate has been forecasted from16 October 2019 to 31 January 2021.
\end{abstract}

KEYWORDS: Time series forecasting, Covid-19, ARIMA, Exchange rate, Sri Lanka, Pandemic

Corresponding Author: Premarathne, W: Email: wasantha@kdu.ac.lk 


\section{INTRODUCTION}

The coronavirus that caused the COVID-19 epidemic originated in Wuhan, China. At present, it has engulfed nearly the whole world, causing unimaginable loss of lives and economic uncertainties. Most countries face economic disputes because they maintain lockdowns and island-wide curfews to tackle the spread of the virus (Wetsman, 2020). As a result of the unstable economy, businesses are primarily concerned with surviving. Therefore, investors are not encouraged to invest, and they stock money to face future uncertainties. This situation will increase the USD sell exchange rate because of low supply and high demand for USD. The Coronavirus pandemic has adversely affected the countries excessively relying on exports and experiencing debt burdens. The countries facing debt burdens are adversely affected due to the severe coercion on foreign exchanges leading to currency devaluation. Since Sri Lanka is a small open economy, fluctuations in exchange rates directly affect domestic price levels and international trade (Central Bank of Sri Lanka, 2006). USD sell exchange rate in Sri Lankan felled to the value of Rs.200.00 for the first time in history on the 8th of April 2020.

Since a country's exchange rates are considered a key financial variable that plays a significant role in the economy, a timely forecast of movements in the exchange rates is required (Rao \& Sahoo, 2020). Analysing the exchange rate movements is essential to provide useful statistical information to the stakeholders participating nationally and internationally (Rao \& Sahoo, 2020). Therefore, this study illustrates US Dollar sales exchange rates in Sri Lanka during the impact of the COVID-19 outbreak by utilising a time series data analysis with the help of EViews software.

\section{LITERATURE REVIEW}

COVID-19 impacts the economy by resulting in unemployment and the devaluation of currency (Yilmazkuday, 2020). Because catastrophes are inherently unexpected, it is difficult to depend entirely on the accuracy and trustworthiness of predictions in such circumstances. Also, disease outbreak is an alternative channel of exchange rate behaviour (Iyke, 2020). The impact of the present global pandemic COVID-19 on the exchange rates in Papua New Guinea was difficult to assess since the country has been experiencing a lack of US Dollars since 2016 (Odhuno, 2020). Using time-series data analysis, Dineri et al. (2020) investigated the correlation between the number of COVID-19 cases and fatalities and the exchange rate. After conducting the cointegration test, they identified no significant relationship between new cases, deaths, and exchange rates. According to Dineri \& Çütçü (2020), the reason for the increase in the exchange rate in Turkey was mainly due to the negative consequences of the country's economic uncertainty during the pandemic. Indonesia has experienced a decrease in exports and an increase in imports during the pandemic period, which has caused a decrease in foreign exchange reserves. Indonesia has imported personnel protection equipment and medicine related to coronavirus (Catherine, Zaini, \& Angelia, 2020). The main reason for the burst in the US Dollar exchange rate was the investors' panic behaviour due to the COVID-19 outbreak.

Furthermore, global uncertainty creates issues for the assets of the investors in financial and capital markets. The study shows a direct relationship between Covid 19 and Rupiah exchange rate. Greater the number of causalities weaker the Indonesian Rupiah exchange rate with the US Dollar. Finally, the study has suggested reducing imports and exports to increase the Rupiah Exchange rate by enhancing foreign exchange reserves (Catherine, Zaini, \& Angelia, 2020).

A Generalised Auto-Regressive Conditional Heteroskedasticity (GARCH) model and a feedforward neural network using the backpropagation algorithm as ANN model, Nanayakkara, Chandrasekaran, and Jayasundara (2014) forecasted the daily currency exchange rate of the US dollar versus Sri Lankan rupee. Ayekple et al. (2015) performed a time series analysis of the exchange rates of Ghanaian Cedi against US Dollars. They carried it out by implying Random Walk (RW) 
Model and ARIMA model. In this study, the exchange rates had become nonstationary. Therefore, the researchers had used first differencing to convert nonstationary into stationary. Box-Jenkins model was used to find out the most suitable model for forecasting. In order to find the Box Jenkins model, $\mathrm{ACF}$ and a sample PACF were used, and it helped to characterise the stationary time series. Ayekple et al. (2015) highlighted that the Box -Jenkins three-stage procedure of selecting a proper ARIMA model could be applied to derive accurate and reliable estimations and predictions for a univariate time series. The three stages were namely (i) identification, (ii) estimation, and (iii) diagnostic checking stage. Ayekple et al. (2015) have employed the least square method to estimate the parameters of the model developed to analyse the USD exchange rates in Ghana. Ogbonna (2018) applied the ARIMA model for modeling the daily USD sell exchange rate in Nigeria from 2016 to 2017. The study results showed that $\operatorname{ARIMA}(0,1,1)$ with a constant value $(0.3171)$ is considered the most suitable model. Augmented Dickey-Fuller test (ADF) and Philips-Perron test (PP) aided in checking whether the time series is stationary or nonstationary. Autocorrelation and partial autocorrelation functions helped to identify the best suited ARIMA model. The Ljung Box test evaluated the model's accuracy (Ogbonna, 2018). Zeleke (2014) has examined the monthly average USD exchange rate in Rwanda with the help of the Box and Jenkins approach from the beginning of 2003 to the end of 2012. According to the study, out of the Auto-Regressive model (AR), Moving Average model (MA), and Autoregressive Moving Average model (ARMA), which was the most suitable model to examine the average Rwanda Francs against US Dollars. The exchange rate depreciation was mainly due to the decrease in exports and increase in imports in Rwanda.

Gupta \& Pradeep (2018) studied the behaviour of the daily USD exchange rate in India between 20 March 2003 to 20 April 2018. EMDs, ACFs, PACS, Support Vector Regression, Neural Networks, and Additive Regression were studied and compared to determine the best method for estimating the exchange rate. According to the study, the results gathered from
SVR and linear regression provide much better results than Neural networks. The results obtained from the ARIMA model were not satisfactory, but the amount of error caused by the ARIMA model was low (Gupta \& Pradeep, 2018). Al Sameeh \& Sayed (2020) has forecasted the USD exchange rate in Sudan using the ARIMA model. The research has used ADF, correlogram, and ARIMA to fit the best model for modelling and forecasting the exchange rate. After the initial differencing, both the ADF and the correlogram for the exchange rate data became stationary. After examining the model's selection criteria, the research had concluded that ARIMA $(1,1,0)$ is the best model to forecast exchange rate data in Sudan. Further, Al Sameeh \& Sayed (2020) mentioned that the Box-Jenkins approach is more appropriate for modeling and forecasting exchange rates. Mihaela (2012) has stated that predictions based on the AR model generate overestimated exchange rates, and it is one of the major deficiencies of the ARIMA model. Moreover, the researcher has recommended the Diebold-Mariano test to assess predictive accuracy. Although several studies on how politics, war, natural disasters, etc. impact USD exchange rates, there were few studies on how pandemics affect USD exchange rates. COVID-19 epidemic significantly impacts the USD exchange rate in Sri Lanka. However, a lack of study still examines the impact of COVID-19 on US Dollar exchange rates in Sri Lanka. Therefore, this study attempts to fulfill the gap by examining the impact of COVID19 on USD exchange rates in Sri Lanka by utilising time-series data analysis techniques.

\section{METHODOLOGY}

For the research, the Central Bank of Sri Lanka provided daily US dollar exchange rates from November 19, 2019, to October 18, 2020. ARIMA model, with the help of EViews software, conducted the time series analysis and forecasting. Various assumptions are needed while doing a time series analysis: the time-series variance and mean stay are constant throughout the period, the error term distribution is random, and the variance and means are constant at a specific time. Before doing a time 
series analysis and forecasting, it is necessary to complete the following steps: determine seasonality, stationarity, model identification, diagnostics, and residual analysis (Khalid, 2020). Also, it is important to visualise the time series data since it helps to identify the structural breaks and the seasonality of the time series (Erica, 2019). Box-Jenkins ARIMA and Vector Autoregressive models are frequently used for time series analysis across the globe (Erica, 2019). Therefore, in this study ARIMA method was used to analyse and forecast the time series. Timeseries graphs help to visualize how the daily USD sell exchange rates are deviating against Sri Lankan Rupee values and identify the seasonality and stationarity. A regressions analysis by EViews derived coefficient, volatility, adjusted r-squared, AIC, and SBIC.

The first step in conducting a time series analysis and forecasting is to test for the seasonality of the time series. Seasonality can be defined as periodic fluctuations or patterns that repeat within a period (Markoulis, Katsikides, \& Hassapis, 2019). The purpose of the seasonality test is to check for seasonal movements in a time series and conclude whether to adjust it or not (JDemetra, 2020). Straight after conducting the seasonality test, a stationarity test was conducted. The term stationary defines constant mean and variation throughout the series. Moreover, stationary becomes beneficial since predicting the future using past observations (Jebb et al. (, 2015). In order to determine if a time series is stationary or not, the $\mathrm{ADF}$ test is the most frequent unit root test that one can be used (Chaudhary, 2020). The unit root test is a test of stationarity (or nonstationary) that has become widely well-known over the past several years. Before doing an ARIMA analysis, it is necessary to transform data into a stationary state. De-trending is necessary if the data are trending (Ngozi, 2018). In the ADF test, if the mean and the autocovariance of the time series data do not depend on time, it is identified as stationary. If any series is not stationary, it is nonstationary or unit root. The $\mathrm{ADF}$ test is very important in time series analysis because the standard assumptions will not be valid if the model is not stationary (unit root). ARIMA's time series forecasting relies on stationary data (Chaudhary, 2020). In order to undertake an ARIMA approach (also known as a Box Jenkin's model), the first step is to determine what kind of model is needed. Autoregressive Integrated Moving Average (ARIMA) model is the widely used forecasting model to predict time series. ARIMA is capable of analysing different standard temporal structures in time series data. It defines a particular time series based on past values using its lags and lag forecasting errors (Loukas, 2020). Using the Autocorrelation plots and the Partial autocorrelation plots can identify the Auto-Regressive (AR) and Moving Average (MA) parameters that are to be used to build the model (Khalid, 2020).

Partial autocorrelation yields AR parameters. The partial autocorrelation summarises the connection between data in a time series and previous observations, ignoring the intervening observations (Brownlee, 2017). AR use observations gained from previous time steps as inputs for the regression equation to predict the amount at the next time step (Brownlee, 2017). Autocorrelation creates MA parameters. The degree of similarity among the relevant time series data and a lagged version of the relevant time series data over consecutive time intervals are represented mathematically by the autocorrelation. Instead of using two contrasting time series, autocorrelation uses a lagged version of the same time series. The relationship between the variable's past and current values can also be measured using autocorrelation (Smith, 2020). Averages calculated using the sequential segment data points of the time series values are the MA parameters (Frost, 2020). After choosing the suitable ARIMA model and before running the time series forecasting, a diagnostic test must be conducted to determine whether any AR and MA values have been left out. This step determines whether the model suits the data, estimates residual, captures Autocorrelation Function and Partial Autocorrelation Function residual, and applies a diagnostic test to validate the model and select the best among other models (Marilena, 2015).

Determining whether the residuals estimated for 
models are white noise is considered as one of the simplest forms of choosing a model (Marilena, 2015). Moreover, supposing it has been estimated as white noise, it could be accepted unless there would be autocorrelation of errors which need a return to the identification stage and rectify the error by adding several lags (Marilena, 2015). Residual diagnostic test and the Ljung-Box test are the main methods used to conduct the model diagnostic test for the ARIMA method. Residuals in time series are used to verify whether the model has adequately captured relevant information while analysing what has been left out after fitting a model (Hyndman, 2018). The residuals' autocorrelations might be used to show the correlogram perspective of the residuals (University of Washington, 1997). Furthermore, residuals could be derived by the difference between the actual and the fitted value of the dependent variable. Therefore, it signals likely errors that the regression might experience during forecasting (University of Washington, 1997).

The Ljung - Box test, also known as modified BoxPierce, or the Box test, is used to test the absence of serial autocorrelation, up to a particular lag (Glen, 2018). The test is used to determine whether errors were white noise or not and whether it has more reason behind them. Also, to check whether autocorrelations for the errors or residuals were nonzero (Glen, 2018), forecasting is used as a technique that uses past data as inputs to predict the future direction (Tuovila, 2020). The ARIMA forecasting model had gained wide popularity because of its reliability and success in forecasting (Gujarati, 2009). Validity can be measured as external or measurement validity and is mainly focused on concluding on whether the findings of the research are really as they appear to be. It is required to compute the validity of the measurement to recognise what has been assumed to measure.

\section{DATA ANALYSIS}

A correlogram determines whether the study is seasonal or nonseasonal. In order to get a summary of correlation between two time periods, a correlogram may be used (Glen, 2016).

\begin{tabular}{|c|c|c|c|c|c|c|c|c|}
\hline \multicolumn{2}{|c|}{ Autocorrelation } & \multicolumn{3}{|c|}{ Partial Correlation } & \multirow{2}{*}{$\frac{\mathrm{AC}}{0.980}$} & \multirow{2}{*}{$\begin{array}{c}\text { PAC } \\
0.980\end{array}$} & \multirow{2}{*}{$\begin{array}{l}\text { Q-Stat } \\
210.23\end{array}$} & \multirow{2}{*}{$\begin{array}{c}\text { Prob } \\
0.000\end{array}$} \\
\hline 15 & & 15 & & 1 & & & & \\
\hline if & & $\square$ & 1 & 2 & 0.951 & -0.233 & 409.05 & 0.000 \\
\hline 18 & & if & & 3 & 0.919 & -0.021 & 595.84 & 0.000 \\
\hline If & & 1. & 曰 & 4 & 0.895 & 0.193 & 773.88 & 0.000 \\
\hline 1 & & 10 & $\sqrt{1}$ & 5 & 0.872 & -0.076 & 943.72 & 0.000 \\
\hline 18 & & 1] & 1 & 6 & 0.849 & -0.030 & 1105.5 & 0.000 \\
\hline 18 & $\square$ & 1] & 1 & 7 & 0.822 & -0.082 & 1257.7 & 0.000 \\
\hline 18 & 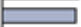 & 므 & 1 & 8 & 0.788 & -0.168 & 1398.2 & 0.000 \\
\hline If & $\square$ & C & 1 & 9 & 0.747 & -0.120 & 1525.1 & 0.000 \\
\hline If & $\square$ & $1)$ & וב & 10 & 0.707 & 0.050 & 1639.3 & 0.000 \\
\hline 18 & $\square$ & 10 & 1 & 11 & 0.669 & -0.038 & 1742.2 & 0.000 \\
\hline If & $\rightleftarrows$ & 18 & 1 & 12 & 0.633 & -0.030 & 1834.8 & 0.000 \\
\hline 18 & $\square$ & 1 & 1 & 13 & 0.594 & -0.093 & 1916.8 & 0.000 \\
\hline If & $\square$ & 10 & 1 & 14 & 0.552 & -0.052 & 1987.9 & 0.000 \\
\hline If & $\square$ & 1 & וp & 15 & 0.511 & 0.070 & 2049.1 & 0.000 \\
\hline If & $\square$ & 11 & 1 & 16 & 0.471 & -0.015 & 2101.3 & 0.000 \\
\hline if & $\square$ & 1 & 1 & 17 & 0.434 & 0.055 & 2146.0 & 0.000 \\
\hline 18 & $\square$ & if & 1 & 18 & 0.399 & -0.026 & 2183.9 & 0.000 \\
\hline 1 & $\square$ & 1 & 11 & 19 & 0.367 & 0.039 & 2216.1 & 0.000 \\
\hline if & $\boxminus$ & 11 & 1 & 20 & 0.334 & -0.002 & 2242.9 & 0.000 \\
\hline 1 & 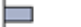 & 11 & 1 & 21 & 0.301 & -0.007 & 2264.9 & 0.000 \\
\hline 1 & 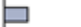 & 1 & 1 & 22 & 0.269 & 0.002 & 2282.5 & 0.000 \\
\hline 18 & 曰 & 11 & 1 & 23 & 0.239 & -0.002 & 2296.4 & 0.000 \\
\hline If & 曰 & 10 & 1 & 24 & 0.210 & -0.056 & 2307.3 & 0.000 \\
\hline it & 口 & 1 & 1 & 25 & 0.184 & 0.044 & 2315.7 & 0.000 \\
\hline If & 曰 & 1 & 1 & 26 & 0.160 & 0.016 & 2322.0 & 0.000 \\
\hline if & & 11 & 11 & 27 & 0.140 & 0.027 & 2326.9 & 0.000 \\
\hline 18 & & 1 & ון & 28 & 0.123 & 0.082 & 2330.7 & 0.000 \\
\hline If & & 11 & 1 & 29 & 0.109 & -0.009 & 2333.7 & 0.000 \\
\hline 18 & & 11 & 1 & 30 & 0.096 & -0.007 & 2336.0 & 0.000 \\
\hline If & gi & 11 & 11 & 31 & 0.084 & 0.020 & 2337.8 & 0.000 \\
\hline 1 & bi & 11 & 1 & 32 & 0.072 & -0.012 & 2339.1 & 0.000 \\
\hline 10 & ון & 10 & 1 & 33 & 0.061 & -0.037 & 2340.1 & 0.000 \\
\hline 10 & 1 & 14 & & 34 & 0.051 & -0.020 & 2340.7 & 0.000 \\
\hline 11 & 11 & 10 & 1 & 35 & 0.040 & -0.055 & 2341.2 & 0.000 \\
\hline 1) & 11 & 11 & & 36 & 0.031 & -0.016 & 2341.4 & 0.000 \\
\hline
\end{tabular}

Figure 1: Correlogram for USD sell exchange rate Source: Data library of the Central Bank of Sri Lanka (2020)

Figure 1 represents the correlogram for the USD sell exchange rate. If the inputted time series is seasonal, the autocorrelation plot will display repeating patterns with lags moving up and down (Corrie, 2015). The gradual decline of the autocorrelation represents nonstationary time series. A correlogram should be developed using the difference to make it 

stationary (Chekwas, 2020). According to Figure 1, there is no such pattern shown by the autocorrelation containing 36 lags. Therefore, the time series is considered nonseasonal.

Table 1: ADF test results for USD sell exchange rate Source: Compiled by authors (2020)

\begin{tabular}{|c|c|c|c|c|}
\hline & & & t-Statistic & Prob.* \\
\hline \multicolumn{3}{|c|}{ Augmented Dickey-Fuller test statistic } & -1.709328 & 0.4251 \\
\hline \multirow[t]{3}{*}{ Test critical values: } & $1 \%$ level & & -3.461178 & \\
\hline & $5 \%$ level & & -2.874997 & \\
\hline & $10 \%$ level & & -2.574019 & \\
\hline \multicolumn{4}{|c|}{ *MacKinnon (1996) one-sided p-values. } & \\
\hline Variable & $\begin{array}{r}\text { Coefficien } \\
\mathrm{t}\end{array}$ & Std. Error & $\mathrm{t}$-Statistic & Prob. \\
\hline SER(-1) & -0.019618 & 0.011477 & -1.709328 & 0.0889 \\
\hline $\mathrm{D}(\mathrm{SER}(-1))$ & 0.282296 & 0.066607 & 4.238229 & 0.0000 \\
\hline $\mathrm{D}(\mathrm{SER}(-2))$ & 0.071691 & 0.069393 & 1.033117 & 0.3028 \\
\hline $\mathrm{D}(\mathrm{SER}(-3))$ & -0.253000 & 0.066922 & -3.780497 & 0.0002 \\
\hline $\mathrm{C}$ & 3.691844 & 2.147316 & 1.719283 & 0.0871 \\
\hline R-squared & 0.154122 & \multicolumn{2}{|c|}{ Mean dependent var } & 0.025133 \\
\hline Adjusted R-squared & 0.137777 & \multicolumn{2}{|c|}{ S.D. dependent var } & 0.692004 \\
\hline S.E. of regression & 0.642567 & \multicolumn{2}{|c|}{$\begin{array}{c}\text { Akaike info } \\
\text { criterion }\end{array}$} & 1.976610 \\
\hline Sum squared resid & 85.46865 & \multicolumn{2}{|c|}{ Schwarz criterion } & 2.055775 \\
\hline Log likelihood & -204.5207 & \multicolumn{2}{|c|}{$\begin{array}{l}\text { Hannan-Quinn } \\
\text { criteria. }\end{array}$} & 2.008607 \\
\hline F-statistic & 9.429057 & \multicolumn{2}{|c|}{ Durbin-Watson stat } & 1.923240 \\
\hline Prob(F-statistic) & 0.000001 & & & \\
\hline
\end{tabular}

According to Table 1, the term Durbin Watson stat calculates the serial correlation in the residuals. Akaike Info Criteria (AIC) is used as a model selection criterion for "non-nested alternatives." AIC with minimum value has been chosen to select the most suitable ARIMA model for example, selecting the smallest value of AIC would help to choose the length of the lag distribution. Schwarz Criterion could be used as an alternative to the AIC (EViews, 2019). Hannan-Quinn Criterion (HQ) could also be considered a penalty function that imposes a larger penalty for additional coefficients, same as Schwartz Criterion. F-statistic is a form of a testing hypothesis, and it has been used when all the slope coefficients under regression are zero (excluding the intercept and coefficient) (EViews, 2019).

Augmented Dickey-Fuller (ADF) test was utilised to conduct the stationarity test. Table 1 represents the ADF test results. According to the results, the Augmented Dickey-Fuller Test Statistic is -1.709328 Here, the absolute value is considered and the sign is not considered. If the absolute value was lower than the critical test value, the test could not reject the null hypothesis. Also, if the probability value is less than $5 \%$, the null hypothesis can be rejected (Inani, 2015).
According to the above calculation, the estimated probability value of 0.4251 was higher compared to 0.05 . Therefore, the results have concluded that the time series SER has a unit root. Therefore, it could be concluded that the series is not stationary. According to (Fuhad \& Jahanara, 2019) ADF test is accurate and reliable for determining the nature of the data. Further, they have recommended using first differencing to convert nonstationary time series into stationary time series.

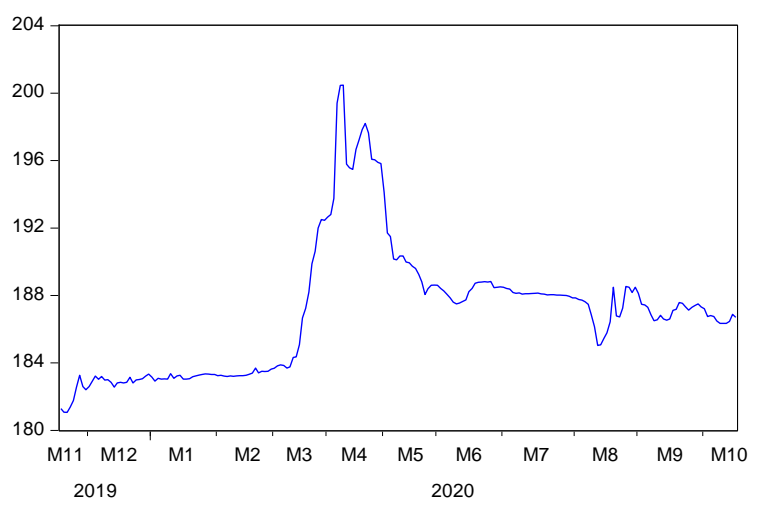

Figure 2: USD sell exchange rate

Source: Data library of the Central Bank of Sri Lanka (2020)

Figure 2 illustrates the graphical representation of the USD sell exchange rate in the form of nonstationary time series. The ADF test was conducted at its first difference to make the time series stationary.

Table 2: ADF test results at its first difference Source: Compiled by authors (2020)

\begin{tabular}{|c|c|c|c|c|}
\hline \\
\hline & & & t-Statistic & Prob.* \\
\hline \multicolumn{3}{|c|}{ Augmented Dickey-Fuller test statistic } & -9.807431 & 0.0000 \\
\hline \multirow[t]{3}{*}{\begin{tabular}{|l|} 
Test critical \\
values:
\end{tabular}} & $1 \%$ level & & -3.461178 & \\
\hline & $5 \%$ level & & -2.874997 & \\
\hline & $10 \%$ leve 1 & & 019 & \\
\hline \multicolumn{5}{|c|}{${ }^{*} \mathrm{MacK}$ innon (1996) one-sided p-values. } \\
\hline Variable & Coefficient & Std. Error & t-S tatistic & Prob. \\
\hline $\mathrm{D}(\mathrm{SER}(-1))$ & -0.921266 & 0.093936 & -9.807431 & 0.0000 \\
\hline $\mathrm{D}(\mathrm{SER}(-1), 2)$ & 0.200193 & 0.082346 & 2.431124 & 0.0159 \\
\hline $\mathrm{D}(\mathrm{SER}(-2), 2)$ & 0.264056 & 0.066916 & 3.946089 & 0.0001 \\
\hline $\mathrm{C}$ & 0.022155 & 0.044401 & 0.498981 & 0.6183 \\
\hline R-squared & 0.405213 & \multicolumn{2}{|c|}{ Mean dependent var } & -0.002314 \\
\hline $\begin{array}{l}\text { Adjusted R- } \\
\text { squared }\end{array}$ & 0.396634 & \multicolumn{2}{|c|}{ S.D. dependent var } & 0.83104 \\
\hline $\begin{array}{l}\text { S.E. of } \\
\text { regression }\end{array}$ & 0.645528 & \multicolumn{2}{|c|}{ Akaike info criterion } & 1.981193 \\
\hline $\begin{array}{l}\text { Sum squared } \\
\text { resid }\end{array}$ & 86.67504 & \multicolumn{2}{|c|}{ Schwarz criterion } & 2.044524 \\
\hline Log likelihood & -206.0064 & \multicolumn{2}{|c|}{ Hannan-Quinn criter. } & 2.006790 \\
\hline F-statistic & 47.23502 & \multicolumn{2}{|c|}{ Durbin-Watson stat } & 1.925540 \\
\hline $\begin{array}{l}\text { Prob(F- } \\
\text { statistic) }\end{array}$ & 0.000000 & & & \\
\hline
\end{tabular}


A similar method was used by Fuhad \& Jahanara (2019) and Sameeh \& Sayed (2020). They had used ADF, correlogram, and ARIMA to fit a suitable model for modelling and forecasting time series.

According to Table 2, the absolute value of the ADF test statistic is 9.807431, and it is higher than the critical test value of 3.461178 . Also, the probability value is less than 0.05 . Therefore, it can be concluded that the time series is stationary.

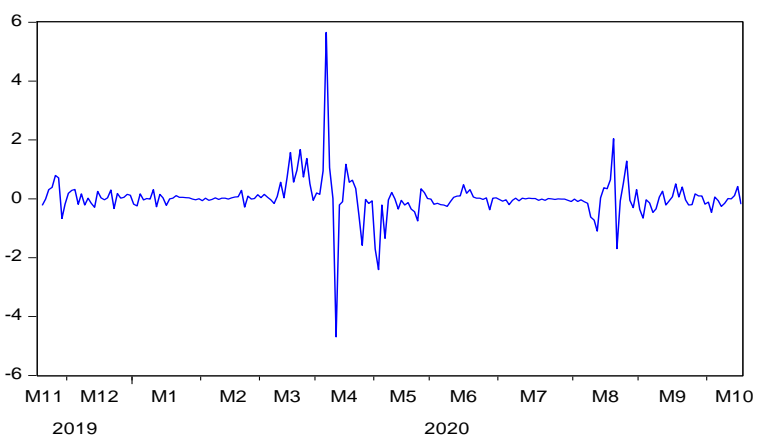

Figure 3: Differenced USD sell exchange rate Source: Data library of the Central Bank of Sri Lanka (2020)

\begin{tabular}{|c|c|c|c|c|c|c|}
\hline Autocorrelation & Partial Correlation & & $\mathrm{AC}$ & PAC & Q-Stat & Prob \\
\hline $1 \boxminus$ & $1 \emptyset$ & 1 & 0.279 & 0.279 & 16.930 & 0.000 \\
\hline ומ ו & $1 \longdiv { 1 }$ & 2 & 0.067 & -0.011 & 17.920 & 0.000 \\
\hline , & $\theta_{1}$ & & -0.227 & -0.263 & 29.249 & 0.000 \\
\hline 11 & 1 & & -0.012 & 0.140 & 29.282 & 0.000 \\
\hline ון ו ו & ון ו & 5 & 0.048 & 0.054 & 29.790 & 0.000 \\
\hline 只 & ון ו ו & 6 & 0.183 & 0.091 & 37.240 & 0.000 \\
\hline . & 1日 & 7 & 0.187 & 0.150 & 45.101 & 0.000 \\
\hline 1曰 & 10 & 8 & 0.201 & 0.137 & 54.224 & 0.000 \\
\hline$1 \longdiv { 1 }$ & 1 & 9 & -0.024 & -0.095 & 54.350 & 0.000 \\
\hline 11 & 11 & 10 & -0.046 & 0.020 & 54.830 & 0.000 \\
\hline 1दा & 1 & 11 & -0.050 & 0.030 & 55.396 & 0.000 \\
\hline 1 & ון ו & 12 & 0.094 & 0.034 & 57.436 & 0.000 \\
\hline । & 111 & 13 & 0.104 & 0.023 & 59.953 & 0.000 \\
\hline 11 & 미 & 14 & -0.033 & -0.160 & 60.212 & 0.000 \\
\hline 1) & 11 & 15 & -0.036 & 0.011 & 60.518 & 0.000 \\
\hline C I & 디 & 16 & -0.138 & -0.130 & 64.998 & 0.000 \\
\hline 1 أI & 10 & 17 & -0.058 & -0.037 & 65.794 & 0.000 \\
\hline I & 101 & 18 & -0.075 & -0.057 & 67.128 & 0.000 \\
\hline 1' & 10 & 19 & 0.008 & -0.035 & 67.144 & 0.000 \\
\hline $1 \mid 1$ & 111 & 20 & 0.003 & -0.013 & 67.146 & 0.000 \\
\hline 11 & 11 & 21 & -0.018 & -0.022 & 67.221 & 0.000 \\
\hline 10 & 11 & 22 & -0.065 & 0.028 & 68.250 & 0.000 \\
\hline 1] & 1 & 23 & -0.045 & 0.016 & 68.740 & 0.000 \\
\hline । & 10. & 24 & -0.092 & -0.037 & 70.797 & 0.000 \\
\hline 14. & 111 & 25 & -0.060 & -0.035 & 71.693 & 0.000 \\
\hline वें & 1 । & 26 & -0.120 & -0.063 & 75.235 & 0.000 \\
\hline di & 吅 । & 27 & -0.117 & -0.103 & 78.627 & 0.000 \\
\hline IC] । & 10 & 28 & -0.074 & -0.005 & 80.008 & 0.000 \\
\hline ו1) & 111 & 29 & -0.044 & -0.023 & 80.485 & 0.000 \\
\hline I I & Id & 30 & -0.042 & -0.071 & 80.923 & 0.000 \\
\hline 111 & ון ו & 31 & -0.019 & 0.043 & 81.011 & 0.000 \\
\hline $1 \mid 1$ & 1 & 32 & -0.010 & 0.016 & 81.038 & 0.000 \\
\hline 111 & 1 & 33 & -0.025 & 0.003 & 81.200 & 0.000 \\
\hline 111 & 1 & 34 & -0.011 & 0.076 & 81.230 & 0.000 \\
\hline 1 & 1 & 35 & -0.016 & 0.023 & 81.294 & 0.000 \\
\hline III & III & 36 & -0.037 & -0.036 & 81.652 & 0.000 \\
\hline
\end{tabular}

Figure 4: Correlogram at first difference. Source: Compiled by authors (2020)
Figure 3 illustrates the stationary time series, which revolves around the mean of zero. If a horizontal straight line is drawn from zero, it can be seen that the series exhibits mean reversion around zero (Ngozi, 2018). Therefore, the differenced sell exchange rate can be considered as stationary at first difference.

As indicated in Figure 1, the autocorrelation is gradually declining, and it is considered as a nonstationary set of time series. Earlier, by conducting the Augmented Dickey-Fuller method at its first differences, it was identified that the time series is converted to stationary. Therefore, the correlogram specification is conducted by running the first difference to make the time series stationary.

Table 3: List of developed models

\begin{tabular}{|c|c|c|c|c|c|}
\hline & $\begin{array}{l}\text { Signific ant } \\
\text { coefficients }\end{array}$ & $\begin{array}{l}\text { Sigma }^{2} \\
\text { (volatility) }\end{array}$ & Adj. $R^{2}$ & AIC & SBIC \\
\hline ARIMA $(1,1,1)$ & 1 & 0.434021 & 0.064664 & 2.040798 & 2.103507 \\
\hline ARIMA $(1,1,3)$ & 3 & 0.403219 & 0.131044 & 1.968229 & 2.030938 \\
\hline $\operatorname{ARIMA}(3,1,1)$ & 3 & 0.406994 & 0.12291 & 1.977528 & 2.040237 \\
\hline ARIMA $(1,1,7)$ & 2 & 0.428 & 0.077639 & 2.027288 & 2.089997 \\
\hline $\operatorname{ARIMA}(7,1,1)$ & 1 & 0.432982 & 0.066903 & 2.038717 & 2.101427 \\
\hline ARIMA $(1,1,8)$ & 3 & 0.412527 & 0.110986 & 1.992359 & 2.055069 \\
\hline $\operatorname{ARIMA}(8,1,1)$, & 1 & 0.422608 & 0.08926 & 2.015396 & 2.078106 \\
\hline ARIMA $(1,1,16)$ & 2 & 0.426026 & 0.081893 & 2.023465 & 2.086175 \\
\hline ARIMA $(16,1,1)$ & 1 & 0.430684 & 0.071857 & 2.034291 & 2.097 \\
\hline $\operatorname{ARIMA}(3,1,3)$ & 1 & 0.440049 & 0.051673 & 2.055284 & 2.117993 \\
\hline $\operatorname{ARIMA}(3,1,7)$ & 2 & 0.425745 & 0.0825 & 2.023704 & 2.086413 \\
\hline $\operatorname{ARIMA}(7,1,3)$ & 2 & 0.432947 & 0.066979 & 2.039869 & 2.102578 \\
\hline $\operatorname{ARIMA}(3,1,8)$ & 3 & 0.415564 & 0.10444 & 2.000955 & 2.063665 \\
\hline ARIMA $(8,1,3)$ & 2 & 0.43003 & 0.073266 & 2.033487 & 2.096196 \\
\hline ARIMA $(3,1,16)$ & 2 & 0.438435 & 0.055152 & 2.052497 & 2.115206 \\
\hline $\operatorname{ARIMA}(16,1,3)$ & 2 & 0.444366 & 0.04237 & 2.065544 & 2.128253 \\
\hline ARIMA $(7,1,7)$ & 1 & 0.450932 & 0.02822 & 2.080258 & 2.142968 \\
\hline ARIMA ( & 2 & 0.43446 & 0.063719 & 2.044233 & 2.106942 \\
\hline $\operatorname{ARIMA}(8,1,7)$ & 1 & 0.438243 & 0.055567 & 2.052299 & 2.115009 \\
\hline ARIMA $(7,1,16)$ & 1 & 0.445159 & 0.040662 & 2.06816 & 2.130869 \\
\hline ARIMA $(16,1,7)$ & 1 & 0.4435 & 0.044237 & 2.064636 & 2.127345 \\
\hline $\operatorname{ARIMA}(8,1,8)$ & 1 & 0.440423 & 0.050869 & 2.058062 & 2.120772 \\
\hline $\operatorname{ARIMA}(8,1,16)$ & 1 & 0.436289 & 0.059777 & 2.049323 & 2.112033 \\
\hline ARIMA $(16,1,8)$ & 1 & 0.436341 & 0.059664 & 2.049442 & 2.112152 \\
\hline ARIMA $(16,1,16)$ & 1 & 0.460914 & 0.006708 & 2.102 & 2.16471 \\
\hline ARIMA $(4,1,1)$ & 1 & 0.438477 & 0.055062 & 2.050949 & 2.113658 \\
\hline $\operatorname{ARIMA}(4,1,3)$ & 2 & 0.449048 & 0.032281 & 2.075228 & 2.137938 \\
\hline ARIMA $(4,1,6)$ & 2 & 0.457058 & 0.015019 & 2.092799 & 2.155509 \\
\hline $\operatorname{ARIMA}(4,1,7)$ & 1 & 0.450734 & 0.028647 & 2.079876 & 2.142585 \\
\hline ARIMA $(4,1,8)$ & 2 & 2646 & 0.046077 & 2.062987 & 2.125696 \\
\hline ARIMA $(4,1,16)$ & 1 & 0.460981 & 0.006565 & 2.102124 & 2.164833 \\
\hline $\operatorname{ARIMA}(1,1,6)$ & 2 & 0.426452 & 0.080976 & 2.023564 & 2.086273 \\
\hline $\operatorname{ARIMA}(3,1,6)$ & 2 & 0.43838 & 0.05527 & 2.051558 & 2.114268 \\
\hline ARIMA $(7,1,6)$ & 1 & 0.447508 & 0.0356 & 2.134825 & 2.097453 \\
\hline ARIMA $(8,1,6)$ & 1 & 0.437189 & 0.057837 & 2.04998 & 2.11269 \\
\hline ARIMA $(14,1,6)$ & 1 & 0.454689 & 0.020123 & 2.088056 & 2.150765 \\
\hline ARIMA $(16,1,6)$ & 1 & 0.449183 & 0.03199 & 2.076549 & 2.139258 \\
\hline ARIMA $(14,1,1)$ & 2 & 0.437953 & 0.056191 & 2.049897 & 2.112606 \\
\hline ARIMA $(14,1,3)$ & 2 & 0.451136 & 0.027781 & 2.079667 & 2.142376 \\
\hline ARIMA $(14,1,7)$ & 1 & 0.451286 & 0.027459 & 2.080924 & 2.143633 \\
\hline ARIMA $(14,1,8)$ & 2 & 0.440757 & 0.050148 & 2.059185 & 2.121894 \\
\hline ARIMA $(14,1,16)$ & 1 & 0.4605 & 0.007601 & 2.101141 & 2.163851 \\
\hline
\end{tabular}

Figure 4 represents the correlogram of USD sell exchange rate at first difference. The data set has become stationary, and some of the lags have become significant since they have passed the standard errorbound line. These significant lags are used to create 
the various models to estimate the most suitable ARIMA model to utilise in further analysis (Corrie, 2015). In Figure 4, both autocorrelation and partial autocorrelation are significant in lag 1, lag 3, lag 7, lag 8 , and lag 16. Autocorrelation is significant in lag 6 and partial autocorrelation is significant in lag 4 and lag 14. A total of 42 models were created by combining the AR and MA values of significant lags.

Table 3 represents the list of models developed based on AR and MA values obtained from significant lags of the correlogram. The significant coefficients, volatility, adjusted $r$ squared, Akaike Info Criterion (AIC), and Schwarz Criterion (SBIC) values were compared among the models to find the most suitable ARIMA model. From the list of models in Table 3, the model with the highest significant coefficient, lowest volatility value, highest adjusted $\mathrm{r}$ squared value, lowest AIC value, and the lowest SBIC value was selected as the best ARIMA model. Therefore, out of all the ARIMA models listed in Table 3, the ARIMA model $(1,1,3)$ consists of the highest significant coefficient, lowest volatility value, highest adjusted $r$ squared value lowest AIC value, and the lowest SBIC value. Therefore, the ARIMA model $(1,1,3)$ was selected as the most suitable ARIMA model for the time series. In the ARIMA model $(1,1,3)$, the first value " 1 " at the left-hand corner represents the AR, the middle value " 1 " shows that there is only one variable in the time series and the last value " 3 " at the right-hand corner represents the MA.

Figure 5 represents the correlogram of the estimated ARIMA model $(1,1,3)$. The residual diagnostic test highlighted that the correlogram is not flat and lag 8 , lag 14, and lag 16 are significant. Therefore, the focus was to capture as many lags as possible without overfitting the ARIMA model. Overfitting involves fitting a more elaborate model than the one estimated to see (Hipel \& McLeod, 1994). There is still information that needs to be captured if there are significant lags after the residual diagnostic. Therefore, the previously estimated ARIMA model needs to be re-estimated. A new model was estimated using the significant AR and MA values generated in
Figure 5.

\begin{tabular}{|c|c|c|c|c|c|}
\hline Autocorrelation & Partial Correlation & $A C$ & PAC & Q-Stat & Prob \\
\hline 10 & 11 & $1-0.024$ & -0.024 & 0.1242 & \\
\hline 1 & ו & 20.071 & 0.070 & 12159 & \\
\hline 1 & 11 & $3-0.032$ & -0.029 & 1.4376 & 0.231 \\
\hline ון ו ו & 1 1 & 40.073 & 0.067 & 2.6027 & 0.272 \\
\hline 1 & 1 & 50.056 & 0.064 & 3.3066 & 0.347 \\
\hline 10 & 10 & $\begin{array}{ll}6 & 0.119\end{array}$ & 0.113 & 6.4672 & 0.167 \\
\hline 15 & 15 & $\begin{array}{lll}7 & 0.107\end{array}$ & 0.112 & 9.0361 & 0.108 \\
\hline 㞋 & $1 曰$ & 80.186 & 0.185 & 16.828 & 0.010 \\
\hline 10 & $1 \sqrt{1}$ & $9-0.037$ & -0.034 & 17.136 & 0.017 \\
\hline 111 & 111 & $10 \quad 0.016$ & -0.017 & 17.197 & 0.028 \\
\hline I I & 1 & $11-0.053$ & -0.070 & 17.846 & 0.037 \\
\hline 1 1 1 & 1 & 120.091 & 0.035 & 19.766 & 0.032 \\
\hline ין & ו & 130.081 & 0.053 & 21288 & 0.031 \\
\hline I & 당 & $14-0.082$ & -0.145 & 22.840 & 0.029 \\
\hline 1 أl & 11 & 150.023 & -0.018 & 22.962 & 0.042 \\
\hline di & - & $16-0.116$ & -0.142 & 26.127 & 0.025 \\
\hline 111 & 111 & $17-0.010$ & -0.023 & 26.151 & 0.036 \\
\hline I & 叫 & $18-0.078$ & -0.075 & 27.581 & 0.035 \\
\hline $1 \mid 1$ & 111 & $19-0.007$ & -0.021 & 27.591 & 0.050 \\
\hline 10 & 111 & $20 \quad 0.000$ & -0.002 & 27.591 & 0.069 \\
\hline 1 & 11 & $21-0.043$ & -0.032 & 28.039 & 0.083 \\
\hline 1 & $1 \mid 1$ & $22-0.063$ & 0.015 & 29.009 & 0.088 \\
\hline 11 & 111 & $23-0.018$ & 0.028 & 29.087 & 0.112 \\
\hline di & 1 & $24-0.110$ & -0.035 & 32.025 & 0.077 \\
\hline 10 & 11 & $25-0.019$ & -0.026 & 32.114 & 0.098 \\
\hline 吅 1 & 101 & $26-0.093$ & -0.041 & 34.246 & 0.080 \\
\hline 리 & 다 1 & $27-0.112$ & -0.123 & 37.373 & 0.053 \\
\hline 101 & 111 & $28-0.038$ & -0.022 & 37.741 & 0.064 \\
\hline 111 & 111 & $29-0.033$ & 0.007 & 38.006 & 0.078 \\
\hline 1 & 101 & $30-0.067$ & -0.062 & 39.131 & 0.079 \\
\hline 10 & । & $31-0.015$ & 0.030 & 39.187 & 0.098 \\
\hline 10 & ו إ 1 & $32-0.003$ & 0.036 & 39.190 & 0.122 \\
\hline ID, & $1 \sqrt{1}$ & $33-0.049$ & -0.002 & 39.816 & 0.133 \\
\hline 111 & ול ו & $34-0.011$ & 0.053 & 39.848 & 0.160 \\
\hline $1 \mid 1$ & ו & $\begin{array}{ll}35 & 0.000\end{array}$ & 0.054 & 39.848 & 0.192 \\
\hline 101 & 111 & $36-0.043$ & -0.025 & 40.331 & 0.211 \\
\hline
\end{tabular}

Figure 5: Correlogram of the model $(1,1,3)$

Source: Compiled by authors (2020)

Table 4: List of re-estimated models

Source: Compiled by authors (2020)

\begin{tabular}{|l|c|c|c|c|}
\hline & $\begin{array}{c}\text { ARIMA } \\
(\mathbf{3 , 1 , 1})\end{array}$ & $\begin{array}{c}\text { AR (1), } \\
\text { MA (3), } \\
\text { MA (8) }\end{array}$ & $\begin{array}{c}\text { AR (1), } \\
\text { AR 14), } \\
\text { MA (3) }\end{array}$ & $\begin{array}{c}\text { AR (1), } \\
\text { AR (16), } \\
\text { MA (3) }\end{array}$ \\
\hline $\begin{array}{l}\text { Significant } \\
\text { coefficients }\end{array}$ & 3 & 3 & 3 & 3 \\
\hline $\begin{array}{l}\text { Sigma } \\
\text { (volatility) }\end{array}$ & 0.406994 & 0.388469 & 0.40032 & 0.397138 \\
\hline Adj. $\mathbf{R}^{\mathbf{2}}$ & 0.12291 & 0.158845 & 0.133184 & 0.140074 \\
\hline AIC & 1.977528 & 1.941631 & 1.970777 & 1.963304 \\
\hline SBIC & 2.040237 & 2.020018 & 2.049164 & 2.041691 \\
\hline
\end{tabular}

Table 4 represents a new set of models estimated using $\mathrm{AR}$ and MA values obtained from the significant lags of the model $(3,1,1)$. Among models in Table 4, the model with the highest significant coefficients, lowest volatility, highest adjusted $\mathrm{R}$ squared, lowest AIC, and the lowest SBIC is the model AR (1), MA (3), MA (8). The newly estimated model should go through the residual diagnostics process. Therefore, relevant correlogram tests were conducted, and the following results were obtained. 
The correlogram of the estimated model AR (1), MA (3), MA (8) was irregular. However, some significant lags were identified from this correlogram. Therefore, it can be concluded that there was still more information to be captured by the correlogram. Autocorrelation and partial autocorrelation were significant in lag 6 , and only partial autocorrelation was significant in lag 14 and lag 27. By combining the AR and MA values of significant lags, a total of 4 models were re-estimated as AR (1) AR (6) MA (3) MA (8), AR (1) MA (3), MA (6) MA (8), AR (1) AR (14) MA (3) MA (8), and AR (1) AR (27) MA (3) MA (8). From the models mentioned above, the model with the highest significant coefficients, lowest volatility, highest adjusted R squared, lowest AIC, and lowest SBIC was shown by the model AR (1) AR (6) MA (3) MA (8). Therefore, the chosen model was again checked using the residual diagnostics test. The correlogram obtained from the residual diagnostics test was irregular. Therefore, there was still left out information to be captured. Therefore, two models were re-estimated by combining the AR and MR values and utilising the significant lags in partial correlation (lag 14 and lag 27). Out of the two re-estimated AR (1) AR (6) AR (14) MA (3) MA (8) and AR (1) AR (6) AR (27) MA (3) MA (8) models, AR (1) AR (6) AR (14) MA (3) MA (8) model has the highest significant coefficients, lowest volatility, highest adjusted R squared, lowest AIC and the lowest SBIC values. The residual diagnostics test for the above-selected model resulted in an irregular correlogram. Only one significant lag was identified (lag 27) when examining the partial correlation. Therefore, AR (1) AR (6) AR (14) AR (27) MA (3) MA (8) model was created using lag 27 and was compared against AR (1) AR (6) AR (14) MA (3) MA (8) model. The highest coefficients, lowest volatility, highest adjusted $\mathrm{r}$ squared, lowest AIC, and lowest SIC values were generated from the model AR (1) AR (6) AR (14) AR (27) MA (3) MA (8). Therefore, a residual diagnostic test was conducted again with the model AR (1) AR (6) AR (14) AR (27) MA (3) MA (8). The residual diagnostics test failed to result in a flat correlogram because lag 27 in autocorrelation and partial correlation was significant. Therefore, re- estimation of the model was necessary. Out of the two re-estimated models, AR (1) AR (6) AR (14) AR (27) AR (11) MA (3) MA (8) and AR (1) AR (6) AR (14) AR (27) MA (3) MA (8) MA (11), AR (1) AR (6) AR (14) AR (27) MA (3) MA (8) MA (11) model show the highest coefficients, lowest volatility, highest adjusted $\mathrm{r}$ squared, lowest AIC, and lowest SIC values. After selecting the appropriate model, a residual diagnostics test was conducted to analyse whether the relevant model was suitable for performing the time series forecasting.

Figure 6 shows that after conducting the residual diagnostics test, the model AR (1), AR (6), AR (14), AR (27), MA (3), MA (8), MA (11) was received a flat correlogram. There are no significant lags present, and all the residuals are uncorrelated. Therefore, Figure 6 indicates that all the necessary information is obtained from the correlogram.

\begin{tabular}{|c|c|c|c|c|c|}
\hline Autocorrelation & Partial Correlation & $\mathrm{AC}$ & PAC & Q-Stat & Prob \\
\hline 1 & 11 & $1-0.028$ & -0.028 & 0.1713 & \\
\hline 11 & ו 1 ו & 20.037 & 0.036 & 0.4686 & \\
\hline 11 & $1\lceil 1$ & 30.006 & 0.008 & 0.4775 & \\
\hline 10 & ו 1 ו & $4 \quad 0.045$ & 0.044 & 0.9156 & \\
\hline ון & $1 \int_{1}$ & 50.053 & 0.055 & 1.5411 & \\
\hline 101 & 11 & $6-0.029$ & -0.029 & 1.7256 & \\
\hline 10 & ול ו ו & 70.082 & 0.077 & 3.2463 & \\
\hline$1 \longdiv { 1 }$ & $1 \longdiv { 1 }$ & $8-0.013$ & -0.009 & 3.2843 & 0.070 \\
\hline 11 & 11 & $9-0.025$ & -0.036 & 3.4307 & 0.180 \\
\hline 17 & $1\} 1$ & $\begin{array}{ll}10 & 0.020\end{array}$ & 0.019 & 3.5249 & 0.318 \\
\hline 11 & 10 & $11-0.001$ & -0.002 & 3.5251 & 0.474 \\
\hline 1 & 1 & $\begin{array}{ll}12 & 0.057\end{array}$ & 0.049 & 4.2831 & 0.509 \\
\hline $1\lceil 1$ & $1 \sqrt{1}$ & $\begin{array}{ll}13 & 0.035\end{array}$ & 0.047 & 4.5719 & 0.600 \\
\hline 10 & 11 & $14-0.011$ & -0.019 & 4.6021 & 0.708 \\
\hline 111 & 11 & $\begin{array}{ll}15 & 0.029\end{array}$ & 0.024 & 4.7999 & 0.779 \\
\hline 1 1 & أ日 & $16-0.091$ & -0.090 & 6.7514 & 0.663 \\
\hline 1 & 111 & $\begin{array}{ll}17 & 0.013\end{array}$ & -0.006 & 6.7939 & 0.745 \\
\hline Id & 1 & $18-0.051$ & -0.046 & 7.4080 & 0.765 \\
\hline 11 & 11 & $\begin{array}{ll}19 & 0.002\end{array}$ & -0.006 & 7.4089 & 0.829 \\
\hline 11 & 10 & $\begin{array}{ll}20 & 0.043\end{array}$ & 0.048 & 7.8504 & 0.853 \\
\hline 101 & 11 & $21-0.025$ & -0.006 & 8.0007 & 0.889 \\
\hline 10 & 111 & $22-0.011$ & -0.019 & 8.0293 & 0.923 \\
\hline 11 & 1 & $23-0.008$ & 0.010 & 8.0434 & 0.948 \\
\hline 1 & 回 & $24-0.076$ & -0.091 & 9.4697 & 0.924 \\
\hline 11 & II & $25-0.027$ & -0.038 & 9.6456 & 0.943 \\
\hline 1ப் & ' & $26-0.091$ & -0.084 & 11.669 & 0.899 \\
\hline 10 & III & $27-0.019$ & -0.034 & 11.760 & 0.924 \\
\hline 11 & 1 & $28-0.009$ & 0.017 & 11.782 & 0.945 \\
\hline 11 & 11 & $29-0.008$ & 0.019 & 11.799 & 0.961 \\
\hline III & 1 & $30-0.056$ & -0.050 & 12.598 & 0.960 \\
\hline 101 & ו إ ו & $\begin{array}{ll}31 & 0.012\end{array}$ & 0.041 & 12.632 & 0.972 \\
\hline $1 \mid 1$ & 111 & $32 \quad 0.031$ & 0.020 & 12.874 & 0.978 \\
\hline 1 & 11 & $33-0.007$ & -0.000 & 12.886 & 0.985 \\
\hline $1 \mid 1$ & $1 \mid 1$ & $34 \quad 0.043$ & 0.044 & 13.352 & 0.987 \\
\hline $1 \mid 1$ & 1 & $\begin{array}{ll}35 & 0.035\end{array}$ & 0.035 & 13.662 & 0.989 \\
\hline 10 & 11 & $36-0.037$ & -0.030 & 14.023 & 0.991 \\
\hline
\end{tabular}

Figure 6: Results of AR (1), AR (6), AR (14), AR (27), MA (3), MA (8), MA (11)

Source: Compiled by authors (2020)

The Ljung box test was conducted to identify whether the $\mathrm{p}$-value of the model is more than 0.05 . As shown 
in Figure 6, each lag of the correlogram of the model AR (1), AR (6), AR (14), AR (27), MA (3), MA (8), MA (11) has a p-value more than 0.05. Therefore, it is concluded that the model AR (1), AR (6), AR (14), AR (27), MA (3), MA (8), MA (11) is the most suitable ARIMA model to forecast the relevant time series. The forecast was based on the adjusted ARIMA model for differenced sell exchange rates using EViews. The model AR (1), AR (6), AR (14), AR (27), MA (3), MA (8), MA (11) was utilised as the adjusted ARIMA model.

Table 5 represents the estimated output of the selected ARIMA model AR (1), AR (6), AR (14), AR (27), MA (3), MA (8), MA (11) using EViews. The model has three significant coefficients, volatility of 0.359219 , adjusted $r$ squared of 0.207077 , AIC value of 1.905545, and SBIC value of 2.046642 .

Table 5: Estimation output of the selected ARIMA model

Source: Compiled by authors (2020)

\begin{tabular}{|c|c|c|c|c|}
\hline Variable & Coefficient & \begin{tabular}{|l} 
Std. Error \\
\end{tabular} & t-Statistic & Prob. \\
\hline $\mathrm{C}$ & 0.029538 & 0.063264 & 0.466899 & 0.6411 \\
\hline $\mathrm{AR}(1)$ & 0.291312 & 0.048705 & 5.981164 & 0.0000 \\
\hline $\mathrm{AR}(6)$ & 0.167853 & 0.076111 & 2.205380 & 0.0285 \\
\hline $\operatorname{AR}(14)$ & -0.101732 & 0.142812 & -0.712348 & 0.4771 \\
\hline $\operatorname{AR}(27)$ & -0.124385 & 0.108585 & -1.145514 & 0.2533 \\
\hline $\mathrm{MA}(3)$ & -0.311496 & 0.046774 & -6.659615 & 0.0000 \\
\hline $\mathrm{MA}(8)$ & 0.260551 & 0.081907 & 3.181060 & 0.0017 \\
\hline MA(11) & -0.177043 & 0.119490 & -1.481651 & 0.1400 \\
\hline $\begin{array}{c}\text { SIGMAS } \\
\mathrm{Q} \\
\end{array}$ & 0.351958 & 0.020129 & 17.48492 & 0.0000 \\
\hline R-squared & 0.254528 & Mean dep & endent var & 0.026956 \\
\hline \begin{tabular}{|l|} 
Adjusted \\
R-squared \\
\end{tabular} & 0.225436 & S.D. depe & ar & 0.688726 \\
\hline \begin{tabular}{|l|} 
S.E. of \\
regression
\end{tabular} & 0.606143 & $\begin{array}{l}\text { Akaike in } \\
\text { criterion }\end{array}$ & & 1.889558 \\
\hline $\begin{array}{l}\text { Sum } \\
\text { squared } \\
\text { resid }\end{array}$ & 75.31900 & \multicolumn{2}{|c|}{ Schwarz criterion } & 2.031118 \\
\hline \begin{tabular}{|l|} 
Log \\
likelihood \\
\end{tabular} & -193.1827 & \multicolumn{2}{|c|}{$\begin{array}{l}\text { Hannan-Quinn } \\
\text { criter. }\end{array}$} & 1.946761 \\
\hline F-statistic & 8.749178 & \multicolumn{2}{|c|}{ Durbin-Watson stat } & 2.056090 \\
\hline $\begin{array}{l}\text { Prob(F- } \\
\text { statistic) }\end{array}$ & 0.000000 & & & \\
\hline
\end{tabular}

Figure 8 shows the forecasted and actual USD sell exchange rates during the prevailing COVID-19 pandemic situation. The forecasted values are denoted in red, and the actual values are depicted in blue. According to Figure 8, the USD sell exchange rate has moved in a range between Rs. 180.00 to Rs. 184.00 during the last quarter of 2019. However, it has dramatically increased during the first three quarters of 2020 resulting Sri Lankan Rupee to fell to its lowest value of Rs.200.00 against the US dollar rates for the first time in history. This was the time that Sri Lanka faced COVOD -19 pandemic situation for the first time.

Table 6 represents the forecasted values, actual values, and forecasting errors. All the forecasted values have obtained a positive forecasting error. The Central Bank of Sri Lanka has not recorded actual USD sell exchange rates on $30^{\text {th }}$ October 2020.

Table 6: Forecasted values vs actual values of USD sell exchange rates

Source: Compiled by authors (2020)

\begin{tabular}{|c|c|c|c|}
\hline Date & $\begin{array}{c}\text { Forecasted } \\
\text { Sell } \\
\text { Exchange } \\
\text { Rate }\end{array}$ & $\begin{array}{c}\text { Actual } \\
\text { Sell } \\
\text { Exchange } \\
\text { Rates }\end{array}$ & $\begin{array}{c}\text { Forecasting } \\
\text { Error }\end{array}$ \\
\hline $19 / 10 / 2020$ & 187.9 & 186.42 & 1.48 \\
\hline $20 / 10 / 2020$ & 188 & 186.48 & 1.52 \\
\hline $21 / 10 / 2020$ & 188 & 186.66 & 1.34 \\
\hline $22 / 10 / 2020$ & 188 & 186.44 & 1.56 \\
\hline $23 / 10 / 2020$ & 188 & 186.49 & 1.51 \\
\hline $26 / 10 / 2020$ & 188.1 & 186.4 & 1.7 \\
\hline $27 / 10 / 2020$ & 188.1 & 186.46 & 1.64 \\
\hline $28 / 10 / 2020$ & 188.1 & 186.46 & 1.64 \\
\hline $29 / 10 / 2020$ & 188.1 & 186.45 & 1.65 \\
\hline $30 / 10 / 2020$ & 188.2 & - & - \\
\hline $02 / 11 / 2020$ & 188.2 & 186.44 & 1.76 \\
\hline $03 / 11 / 2020$ & 188.2 & 186.61 & 1.59 \\
\hline $04 / 11 / 2020$ & 188.2 & 186.55 & 1.65 \\
\hline $05 / 11 / 2020$ & 188.3 & 186.57 & 1.73 \\
\hline $06 / 11 / 2020$ & 188.3 & 186.63 & 1.67 \\
\hline $09 / 11 / 2020$ & 188.3 & 186.64 & 1.66 \\
\hline $10 / 11 / 2020$ & 188.4 & 186.66 & 1.74 \\
\hline $11 / 11 / 2020$ & 188.4 & 186.65 & 1.75 \\
\hline $12 / 11 / 2020$ & 188.4 & 186.7 & 1.7 \\
\hline $13 / 11 / 2020$ & 188.4 & 186.7 & 1.7 \\
\hline & & & \\
\hline
\end{tabular}


280

260

240

220

200

180

(-)

160

140

120

$\begin{array}{llllllll}\text { I II } & \text { III } & \text { IV } & \text { I } & \text { II } & \text { III } & \text { IV }\end{array}$

Forecast: SERF

Actual: SER

Forecast sample: 11/19/2019 10/16/...

Adjusted sample: 12/31/2019 10/16/...

Included observations: 449

Root Mean Squared Error $\quad 4.313983$

Mean Absolute Error $\quad 2.606279$

Mean Abs. Percent Error $\quad 1.356517$

Theil Inequality Coef. 0.011558

Bias Proportion

0.236152

Variance Proportion

0.311936

Covariance Proportion

0.451912

Theil U2 Coefficient

5.912061

Symmetric MAPE

SERF ---- \pm 2 S.E.

Figure 7: Forecasted values of sell exchange rate

Source: Compiled by authors (2020)

204

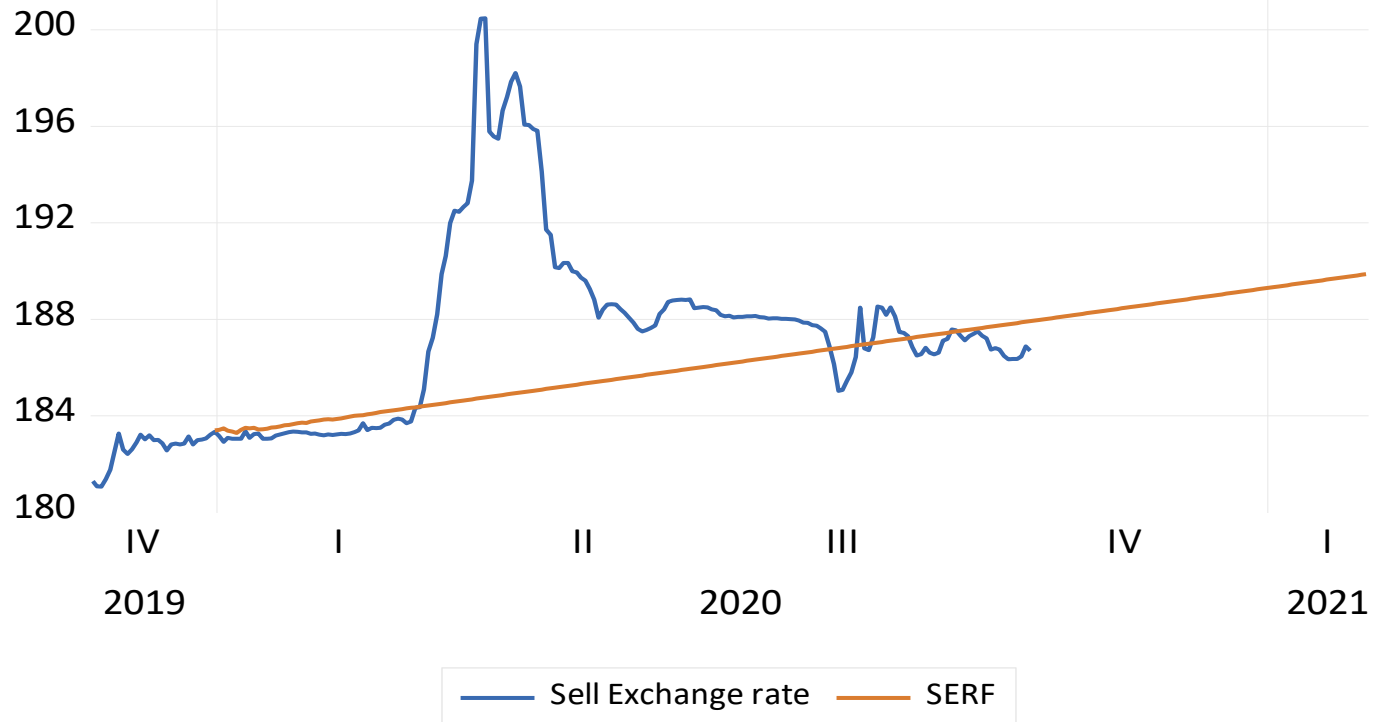

Figure 8: Actual vs the forecasted values

Source: Compiled by authors (2020) 
Table 7: Forecasted USD sell exchange rates from 16.11 .2020 to 31.01.2021

\begin{tabular}{|cc|c|c|cc|}
\hline Date & $\begin{array}{c}\text { Sell } \\
\text { Exchange } \\
\text { Rate }\end{array}$ & Date & $\begin{array}{c}\text { Sell } \\
\text { Exchange } \\
\text { Rate }\end{array}$ & Date & $\begin{array}{c}\text { Sell } \\
\text { Exchange } \\
\text { Rate }\end{array}$ \\
\hline $16 / 11 / 2020$ & 188.5 & $14 / 12 / 2020$ & 189 & $11 / 12021$ & 189.5 \\
\hline $17 / 11 / 2020$ & 188.5 & $15 / 12 / 2020$ & 189 & $12 / 12021$ & 189.5 \\
\hline $18 / 11 / 2020$ & 188.5 & $16 / 12 / 2020$ & 189 & $13 / 1 / 2021$ & 189.5 \\
$19 / 11 / 2020$ & 188.5 & $17 / 12 / 2020$ & 189 & $14 / 12021$ & 189.5 \\
\hline $20 / 11 / 2020$ & 188.6 & $18 / 12 / 2020$ & 189.1 & $15 / 12021$ & 189.6 \\
\hline $23 / 11 / 2020$ & 188.6 & $21 / 12 / 2020$ & 189.1 & $18 / 12021$ & 189.6 \\
\hline $24 / 11 / 2020$ & 188.6 & $22 / 12 / 2020$ & 189.1 & $19 / 12021$ & 189.6 \\
$25 / 11 / 2020$ & 188.6 & $23 / 12 / 2020$ & 189.1 & $20 / 12021$ & 189.6 \\
\hline $26 / 11 / 2020$ & 188.7 & $24 / 12 / 2020$ & 189.2 & $21 / 12021$ & 189.7 \\
\hline $27 / 11 / 2020$ & 188.7 & $25 / 12 / 2020$ & 189.2 & $22 / 12021$ & 189.7 \\
\hline $30 / 11 / 2020$ & 188.7 & $28 / 12 / 2020$ & 189.2 & $23 / 12021$ & 189.7 \\
\hline $01 / 12 / 2020$ & 188.7 & $29 / 12 / 2020$ & 189.2 & $25 / 12021$ & 189.7 \\
\hline $02 / 12 / 2020$ & 188.8 & $30 / 12 / 2020$ & 189.3 & $26 / 12021$ & 189.7 \\
\hline $03 / 12 / 2020$ & 188.8 & $31 / 12 / 2020$ & 189.3 & $27 / 12021$ & 189.8 \\
\hline $04 / 12 / 2020$ & 188.8 & $01 / 12021$ & 189.3 & $28 / 12021$ & 189.8 \\
\hline $07 / 12 / 2020$ & 188.8 & $04 / 1 / 2021$ & 189.3 & $29 / 12021$ & 189.8 \\
$08 / 12 / 2020$ & 188.9 & $05 / 1 / 2021$ & 189.4 & $30 / 12021$ & 189.8 \\
\hline $09 / 122020$ & 188.9 & $06 / 1 / 2021$ & 189.4 & $31 / 12021$ & 189.9 \\
\hline $10 / 12 / 2020$ & 188.9 & $07 / 12021$ & 189.4 & & \\
\hline $11 / 12 / 2020$ & 188.9 & $08 / 12021$ & 189.4 & & \\
\hline
\end{tabular}

Table 7 represents the values that were forecasted until the end of January 2021. It was observed that the USD sell exchange rate will continue to rise at an alarming rate shortly. The USD sell exchange rate will increase up to 189.9 at the end of January 2021.

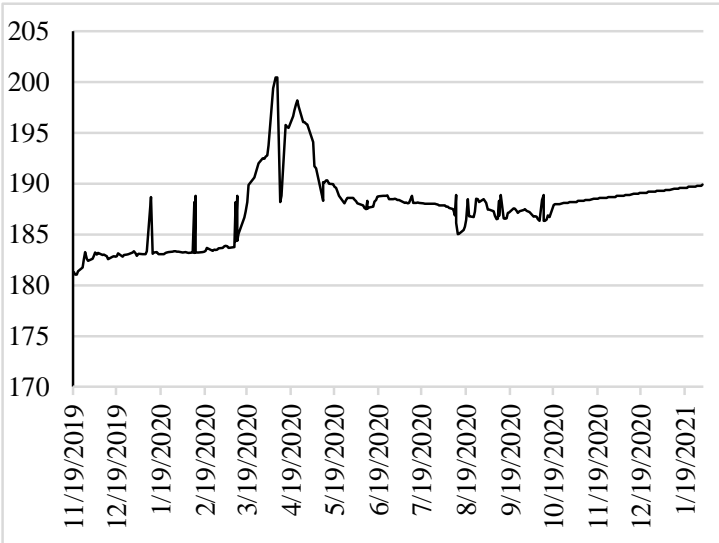

Figure 9: Actual values and forecasted values graphical illustration

Source: Compiled by authors (2020)

Figure 9 illustrates the actual USD sell exchange rate values until 18.10.2020 and the forecasted USD sell exchange rate values from 19.10.2020 onward. It can be observed that the forecasted values have a steady upwards moving line after 19.10.2020.

\section{CONCLUSION}

The study focused on the impact of the COVID-19 pandemic on USD sell exchange rates in Sri Lankan during the period of 19 November 2019 to 18 October 2020 and has forecasted until 31 January 2021. The Augmented Dickey-Fuller Test was utilised to check whether the series is stationary or not. The ARIMA model was utilised as the time series was stationary. Out of all the possible models, ARIMA AR (1) AR (6) AR (14) AR (27) MA (3) MA (8) MA (11) was identified as the most appropriate model to fit the time series. Further, the study has used the adjusted model for forecasting. It was determined that there is an increasing trend of USD sell exchange rate. Even though Sri Lanka is facing negative outcomes of the COVID-19 pandemic, necessary steps should take to minimise the speed of the reduction of rupee value against USD. According to the study, the exchange rate fluctuations are likely being soared up in 2021 if the COVID-19 pandemic situation continued and necessary precautions were not taken to control the devaluation of the Sri Lankan rupees. The study highlighted that if the pandemic continues in 2021, the Sri Lankan rupee will further depreciate against the USD resulting in Rs. 189.9 at the end of January 2021. Therefore, it is necessary to conduct further research to analyse how to avoid the devaluation of the Sri Lankan Rupee sell exchange rate against the USD during the pandemic or any other likely situations which would cause an impact on exchange rates.

\section{REFERENCES}

Adeleye, N. (2018). (EViews10): ARIMA Models (Diagnostics). Nigeria. Retrieved from https://www.youtube.com/watch?v=U7romRtaduE.

Adeleye, N. (2018). (EViews10): ARIMA Models (Estimation). Nigeria. Retrieved from https://www.youtube.com/watch?v=RhjqqessLqg 
Al Sameeh, F., \& Sayed, W. (2020). Forecasting Sudan's Exchange Rate Using Box-Jenkins Approach. doi:10.9790/5728-1403034451.

Ayalasomayajula, V. (2016). Visualising Time Series Data: 7 Types of Temporal Visualisations. Retrieved from atlan: https://humansofdata.atlan.com/2016/11/visualisingtime-series-data/.

Ayekple, Y., Amevialor, J., Harris, E., \& Frempong, N. (2015). Time Series Analysis of the Exchange Rate of the Ghanaian Cedi to the American Dollar. Journal of Mathematics Research, 7, pp 46-47. doi:10.5539/jmr.v7n3 p46.

Brownlee, J. (2017). autoregression-models-timeseries-forecasting-python. Retrieved from machinelearningmastery:

https://machinelearningmastery.com/autoregressionmodels-time-series-forecasting-

python/\#: :text=Autoregression $\% 20$ is $\% 20 \mathrm{a} \% 20$ tim e\%20series,range $\% 20$ of\%20time $\% 20$ series\%20prob lems.

Brownlee, J. (2017). gentle-introductionautocorrelation-partial-autocorrelation. Retrieved from machinelearningmastery: https://machinelearningmastery.com/gentleintroduction-autocorrelation-partial-autocorrelation/.

Catherine, C., Zaini, I., \& Angelia, M. (2020). The impact of Covid-19 pandemic to indonesian exchange rate. Course paper of macro economics, 1 5. doi:10.17605/osf.io/p3zhs.

Catherine, C., Zaini, I., \& Angelia, M. (2020). The impact of Covid -19 pandemic to Indonesian exchange rate. doi:10.17605/ osf.io/p3zhs.

Central Bank of Sri Lanka. (2006). Exchange rate. Pamphlet series no.3 exchange rate, 8. Retrieved from

https://www.cbsl.gov.lk/sites/default/files/cbslweb_ documents/publications/Exchange\%20Rate.pdf.

Chaudhary, M. (2020). medium.com. Retrieved from https://medium.com/:

https://medium.com/@cmukesh8688/why-is- augmented-dickey-fuller-test-adf-test-so-importantin-time-series-analysis-6fc97c6be2f0.

Colombo page news desk. (2020). Sri Lanka rupee slides over Rs. 200 against dollar. Colombo: Sri Lanka Internet Newspaper. Retrieved from http://www.colombopage.com/archive_20A/Apr08_ 1586361471CH.php.

Corporate finance institute. (2015-2020). CFI education inc. Retrieved from corporatefinanceinstitue.com:

https://corporatefinanceinstitute.com/resources/kno wledge/finance/regression-analysis/.

Corrie, K. (2015). How to Identify Seasonality in a Data Set Using the Correlogram (Eviews 8.1). Miami, Florida, United States. Retrieved from https://www.youtube.com/watch?v=O6slZ5QL18M.

CrunchEconometrix (2018). EViews10:Estimate Chow Test for Structural Break. [Recorded by N. Adeleye.]. nigeria. Retrieved from https://www.youtube.com/watch?v=KdjhKwb9xrI\& feature $=$ emb_title.

Central Bank of Sri Lanka (2020). Central Bank of Sri Lanka Retrieved from https://www.cbsl.lk/eresearch/.

Din, M. (2015). ARIMA by Box Jenkins Methodology for Estimation and Forecasting Models in Higher Education. Athens: Athens Institute for Education and Research. doi:10.13140/RG.2.1.1259.6888

Dineri, E., \& Çütçü, İ. (2020). The COVID-19 Process and the Exchange Rate Relation: An Application on Turkey. doi:10.21203/rs.3.rs49026/v1.

Dudovskiy, J. (2019). Research methodology. Retrieved 5 5, 2020, from research-methodology.net: https://research-methodology.net/researchphilosophy/positivism/.

Dudovskiy, J. (2019). Ressearch Methodology. Retrieved May 11, 2020, from researchmethodology.net: https://research- 
methodology.net/research-methodology/researchapproach/inductive-approach-2/.

Econome. (2015). EViews Tutorial - Chow Breakpoint Test. Retrieved from https://www.youtube.com/watch?v=_Sd-aP6Y6HA.

Erica, C. (2019). Introduction to the Fundamentals of Time Series Data and Analysis. Retrieved from APTECH:

https://www.aptech.com/blog/introduction-to-thefundamentals-of-time-series-data-and-analysis/.

EViews. (2019). Regress1-Equation_Output.html. Retrieved from http://www.eviews.com/: http://www.eviews.com/help/helpintro.html\#page/co ntent/Regress1-Equation_Output.html.

Frost, J. (2020). moving-averages-smoothing. Retrieved from statisticsbyjim: https://statisticsbyjim.com/time-series/movingaverages-smoothing/\#comments.

Fuhad Ahmed, J. A. (2019). Time Series Analysis for Predicting the Exchange Rate of USD to BDT. Retrieved from https://scholar.google.com/scholar?hl=en\&as_sdt=0 $\% 2 \mathrm{C} 5 \& \mathrm{q}=$ Time + Series + Analysis + for + Predicting $+\mathrm{t}$ he+Exchange+Rate+of+USD+to+BDT+Fuhad + Ah med $\% 2 \mathrm{C}+\mathrm{Jahanara}+\mathrm{Akter}+\mathrm{Keya} \& \mathrm{btnG}=$.

Ganti, A. (2020). degrees-of-freedom.asp. Retrieved from investopedia.com: https://www.investopedia.com/terms/d/degrees-offreedom.asp\#: :text=Key\%20Takeaways,Degrees $\% 20$ of\%20Freedom\%20refers $\% 20$ to $\% 20$ th e\%20maximum\%20number\%20of\%20logically,suc h\%20as\%20a\%20Chi\%2DSquare.

Glen , S. (2018). ljung-box-test. Retrieved from statisticshowto.com:

https://www.statisticshowto.com/ljung-box-test/.

Glen, S. (2016). correlogram. Retrieved from statisticshowto:

https://www.statisticshowto.com/correlogram/.

Glen, S. (2020). f-statistic-value-test. Retrieved from statisticshowto: https://www.statisticshowto.com/probability-andstatistics/f-statistic-value-test/.

Gov.capital. (2020). forex/usd-lk. Retrieved from gov.capital: https://gov.capital/forex/usd$1 \mathrm{kr} / \#: \sim:$ text $=$ About $\% 20$ the $\% 20$ United $\% 20$ States $\% 2$ 0Dollar\%20\%2F\%20Sri\%20Lankan\%20Rupee\%20 currency $\% 20$ rate $\% 20$ forecast \&text=Future $\% 20$ curr ency\%20rate $\% 20$ of $\% 20$ the,on $\% 202021 \% 20$ Novem ber\%2015\%2C\%20Monday.

Gujarati, D. (2009). Basic econometrics. Tata McGraw-Hill Education. Retrieved from https://scholar.googleusercontent.com/scholar.bib?q =info:hsj0HuapViUJ:scholar.google.com/\&output=c itation\&scisdr=CgUu4zKnELrQp0KiU_Q:AAGBf m0AAAAAX6anS_RJaMuYqQghGNr3QQTGPdmGVAq\&scisig=AAGBfm0AAAAAX6anSK9nfyRN2njvkH_fE_WWauMfyDW\&scisf $=4 \& c t=$ citation\&cd $=-1$.

Gunaratne, S. (1950-2010). Determining the Exchange Rate - Exchange Rate Regimes in Sri Lanka. 60th Anniversary Commemorative Volume of the Central Bank of Sri Lanka, 1-10. Retrieved from https://www.cbsl.gov.lk/sites/default/files/cbslweb_ documents/publications/otherpub/60th_anniversary_ determining_the_exchange_rate.pdf.

Gupta, A., \& Pradeep, A. R. (2018). Time Series Analysis of USD to INR Foreign Exchange Rate. India: Indian Institute of Technology Roorkee. doi:10.13140/RG.2.2.26166.14406.

Health Promotion Bureau. (2020). Health Promotion Bureau. Retrieved from hpb.health.gov.lk: https://hpb.health.gov.lk/covid19-dashboard/.

Hipel, K. W., \& McLeod, A. (1994).: Chapter 7 Diagnostic Checking. In K. W. Hipel, Time Series Modelling of Water Resources and Environmental Systems 45, pp. 235-253. doi:https://doi.org/10.1016/S0167-5648(08)70665-8.

Hyndman, R. (2018). Forecasting: principles and practice. OTexts. Retrieved from https://scholar.google.com/scholar?hl=en\&as_sdt=0 $\% 2 \mathrm{C} 5 \& \mathrm{q}=$ Forecasting $\% 3 \mathrm{~A}+$ Principles+and+Practic 
e+Rob+J+Hyndman+and+George+Athanasopoulos $\& b \operatorname{tnG}=$.

Inani, S. (2015). Checking stationarity by ADF Test in Eviews. Retrieved from https://www.youtube.com/watch?v=F7jVtisHgDs.

Iyke, B. N. (2020).: The Disease Outbreak Channel of Exchange Rate Return Predictability: Evidence from COVID-19. Retrieved from https://scholar.google.com/scholar?hl=en\&as_sdt=0 $\% 2 \mathrm{C} 5 \& \mathrm{q}=\mathrm{Iyke} \% 2 \mathrm{C}+\mathrm{Bernard}+\mathrm{NjindanThe+Disease}$ + Outbreak+Channel+of+Exchange+Rate+Return $+\mathrm{P}$ redictabilit.

JDemetra+. (2020). seasonalitytests. Retrieved from sylwiagrudkowska.github:

https://sylwiagrudkowska.github.io/JDemetra-

documentation/pages/case-

studies/seasonalitytests.html\#: :text=Its\%20purpose $\% 20$ is $\% 20$ to $\% 20$ check,tests $\% 20$ can $\% 20$ be $\% 20$ foun $\mathrm{d} \% 20$ here.

Jebb, A., Tay, L., Wang,, W., \& Huang, Q. (2015). Time series analysis for psychological research: Examining and forecasting change. Frontiers in Psychology. doi:10.3389/fpsyg.2015.00727.

Kenton, W. (2020). timeseries.asp. Retrieved from Investopedia:

https://www.investopedia.com/terms/t/timeseries.as p.

Khalid, I. A. (2020). statistical-test-for-time-series. Retrieved from towards data sciences: https://towardsdatascience.com/statistical-test-fortime-series-a57d9155d09b

Khalid, I. A. (2020). statistical-test-for-time-series. Retrieved from towards data science: https://towardsdatascience.com/statistical-test-fortime-series-a57d9155d09b.

Loukas, S. (2020). time-series-forecastingpredicting-stock-prices-using-an-arima-model.

Retrieved from towardsdatascience.com: https://towardsdatascience.com/time-seriesforecasting-predicting-stock-prices-using-an-arimamodel-2e3b3080bd70.
Marilena, D. (2015). ARIMA by Box Jenkins Methodology for Estimation and Forecasting Models in Higher Education. doi:10.13140/RG.2.1.1259.6888.

Meo, M. S. (2016). How to find Structural breaks in model using eviews. Pakistan. Retrieved from https://www.youtube.com/watch?v=6r25S7fjclU.

Mihaela, S. (2012). Modeling and Forecasting the Exchange Rate in Romania. Retrieved from https://www.researchgate.net/publication/22165787 5_Modeling_and_Forecasting_the_Exchange_Rate_ in_Romania.

Nanayakkara, K., Chandrasekara, N. V., \& Jayasundara, D. D. (2014). Forecasting Exchange Rates using Time Series and Neural Network Approaches. European International Journal of Science and Technology, 3, 2. doi:ISSN: 2304-9693.

Ngozi , A. (2018). (EViews10): ARIMA Models (Forecasting). Retrieved from https://www.youtube.com/watch?v=GytfzaIr2iM.

Ngozi, A. (2018). (EViews10):Augmented DickeyFuller Test, Stationarity. Nigeria. Retrieved from https://www.youtube.com/watch?v=ovpHuz6YMLc

Ngozi, A. (2018). (EViews10):Augmented DickeyFuller Test, Stationarity. Retrieved from https://www.youtube.com/watch?v=ovpHuz6YMLc.

O'Brien, R. (1998). An overview of the methodological approach of action research. Theory and Practice of Action Research, 3-7. Retrieved from https://pdfs.semanticscholar.org/d966/4350e9792db ae3fe4842a9459ed1ecce3cab.pdf.

Odhuno, F. (2020). The potential impact of COVID19 on exchange rates in Papua New Guinea. Retrieved from https://www.researchgate.net/publication/34135960 7_The_potential_impact_of_COVID19_on_exchange_rates_in_Papua_New_Guinea.

Ogbonna, C. (2018). A time series analysis of daily exchange rate of US dollar to NAIRA from 20162017 recession period. International Journal of Scientific and Engineering Research. Retrieved from 
https://www.researchgate.net/publication/32706025 9.

Peixeiro, M. (2019). the-complete-guide-to-timeseries-analysis-and-forecasting. Retrieved from towards data science: https://towardsdatascience.com/the-complete-guideto-time-series-analysis-and-forecasting-

70d476bfe 775 .

Prabhakaran, S. (2019). time-series/augmenteddickey-fuller-test/. Retrieved from machinelearningplus.com:

https://www.machinelearningplus.com/time-

series/augmented-dickey-fuller-test/.

PressAcademia. (2018). Pressacademia. Retrieved from pressacademia.org: http://www.pressacademia.org/definition-of-casestudy/.

Rajakaruna, S. (2017). An Investigation on Factors affecting Exchange Rate Fluctuations in Sri Lanka. Staff Studies, 47, 69. doi:10.4038/ss.v47i1.4703.

Smith, T. (2020). autocorrelation.asp. Retrieved from Investopedia:

https://www.investopedia.com/terms/a/autocorrelati on.asp.

Statisctics Solutions. (2020). statistics solutions advancement through clarity. Retrieved from statisticssolutions.com:

https://www.statisticssolutions.com/time-seriesanalysis/.

Stephanie, G. (2016). chow-test. Retrieved from statisticshowto.com:

https://www.statisticshowto.com/chow-test/.

Tumaku, J. (2016): Univariate Time Series Modelling of Cedi-Dollar Nominal Exchange Rate. Asian Journal of Economics, Business, and Accounting. doi:10.9734/AJEBA/2016/28867.

Tuovila,

A.

(2020):

forecasting.asp\#: :text=Forecasting $\% 20$ is $\% 20 \mathrm{a} \% 20$ technique $\% 20$ that, an $\% 20$ upcoming $\% 20$ period $\% 20$ o f\%20time. Retrieved from www.investopedia.com: https://www.investopedia.com/terms/f/forecasting.as p\#: :text=Forecasting $\% 20$ is $\% 20 \mathrm{a} \% 20$ technique $\% 20$ that,an\%20upcoming $\% 20$ period $\% 20$ of $\% 20$ time.

Twin, A. (2020). Investopedia. Retrieved from Investopedia.com:

https://www.investopedia.com/trading/factorsinfluence-exchange-rates/.

University of Washington. (1997). Forecasting Using Eviews. Retrieved from https://faculty.washington.edu/ezivot/introforecast.P DF.

ViData Solutions. (2020). How to Estimate ARIMA Models in Eviews. Nigeria. Retrieved from https://www.youtube.com/watch?v=rdJL9mEPxbs.

Wetsman, N. (2020). Everything you need to know about the coronavirus. The VERGE. Retrieved from https://www.theverge.com/2020/1/23/21078457/cor onavirus-outbreak-china-wuhan-quarantine-whosars-cdc-symptoms-risk.

Yilmazkuday, H. (2020). COVID-19 and Exchange Rates: Spillover Effects of U.S. Monetary Policy. 113. Retrieved from https://scholar.google.com/scholar?hl=en\&as_sdt=0 $\% 2 \mathrm{C} 5 \& \mathrm{q}=\mathrm{COVID}-$

19+and+Exchange+Rates $\% 3 \mathrm{~A}+$ Spillover+Effects+o f+U.S.+Monetary+PolicyYilmazkuday $\% 2 \mathrm{C}+$ Hakan $\& b \operatorname{tnG}=$.

Zeleke, G. (2014). Time series analysis on monthly average Rwanda currency exchange rate against US dollars. Academia publishing. doi:10.15413/jbem.2. 